\title{
EGILS consensus report. Gastric extranodal marginal zone B-cell lymphoma of MALT
}

\author{
A Ruskoné-Fourmestraux, ${ }^{1} \mathrm{~W}$ Fischbach, ${ }^{2} \mathrm{~B} \mathrm{M} \mathrm{P} \mathrm{Aleman,},{ }^{3} \mathrm{H} \mathrm{Boot},{ }^{4} \mathrm{M} \mathrm{O} \mathrm{Du},{ }^{5}$ \\ F Megraud, ${ }^{6} \mathrm{C}$ Montalban, ${ }^{7} \mathrm{M}$ Raderer, ${ }^{8} \mathrm{~A}$ Savio, ${ }^{9} \mathrm{~A}$ Wotherspoon, ${ }^{10}$ on behalf of the \\ EGILS group
}

For numbered affiliations and full list of contributors see end of article.

\section{Correspondence to Agnès Ruskoné-Fourmestraux, Department of Gastroenterology, Hôpital St Antoine, 184 rue du Fg Saint Antoine, 75012 Paris, France; agnes.fourmestraux@sat.aphp. fr}

Dedicated to Brigitte Dragosics.

Revised 9 November 2010 Accepted 17 November 2010

Published Online First

11 February 2011

\section{ABSTRACT}

This consensus report of the EGILS (European Gastro-Intestinal Lymphoma Study) group includes recommendations on the management of gastric extranodal marginal zone B-cell lymphoma of MALT. They are based on data from the literature and on intensive discussions and votings of the experts during their annual meetings.

The EGILS (European Gastro-Intestinal Lymphoma Study) group is a group of clinicians and scientists with a special expertise in the field of gastrointestinal lymphomas. This report summarises consensual clinical evidence gathered by these experts during the collegial multidisciplinary discussions at EGILS' group annual meetings in Paris 2007, Barcelona 2008 and London 2009. The panel consisted of gastroenterologists, medical and clinical haemato- oncologists, pathologists, molecular biologists and microbiologists.

The two persons responsible for the organisation and implementation (AR-F and WF) defined seven topic complexes: histopathology, molecular biology, diagnosis and staging, Helicobacter pylori (H pylori), radiotherapy, chemotherapy and follow-up. Every working group was headed by one or two experts (authors). A literature search was performed within the single groups using a non-systematic approach. Statements were prepared by the heads of the groups and discussed during the above-mentioned meetings. Voting took place and an agreement of $>75 \%$ of the participants was accepted as consensus. Editorial revision of the task force manuscripts was done by the two first authors. The final draft of the manuscript was reviewed and approved by all participants.

Gastric mucosa-associated lymphoid tissue (MALT) lymphoma is a rare disease. As a consequence of this, there are no prospective randomised trials available. Data included original publications and reviews. Abstracts were not considered. The recommendations outlined below do generally not fulfil the criteria for high evidence levels as the application of the GRADE (Grading of Recommendations Assessment, Development and Evaluation. Jaeschke R, BMJ 2008;337:a744) criteria was not possible. Therefore, this paper is a consensus report rather than a guideline.

\section{DIAGNOSIS \\ Histopathology \\ Definition}

Gastric extranodal marginal zone B-cell lymphoma of MALT is a B-cell non-Hodgkin lymphoma that arises in the stomach and has a perifollicular/ marginal zone growth pattern. The lymphoma is derived from marginal zone B-cells and recapitulates the architecture and organisation of native MALT exemplified by the Peyers' patches in the terminal ileum. ${ }^{1-3}$

\section{Synonym}

Gastric MALT lymphoma (this abbreviation will be used in the subsequent text).

\section{Recommendation}

The diagnosis of gastric MALT lymphoma is based on histomorphological criteria according to the WHO classification. A reference pathologist should confirm the diagnosis.

\section{Comment}

In the earliest stage, the neoplastic cells (sometimes known as centrocyte-like cells) adopt a perifollicular distribution, but with time the infiltrate extends into the lamina propria away from the follicles and this may be a helpful diagnostic feature. The neoplastic cells infiltrate into gastric gland epithelium causing eosinophilic change to the epithelial cells and destruction of the architecture (lymphoepithelial lesion). ${ }^{4-6}$

Lymphoid follicles are an ubiquitous finding in MALT lymphoma. The neoplastic cells infiltrate and may overrun these follicles. Sometimes specific colonisation of the germinal centres may occur.

The neoplastic cells have variable morphology including mature round lymphocyte cells resembling germinal centre centrocytes with irregular nuclei, cells with monocytoid/marginal zone B-cell appearance and cells with lymphoplasmacytic appearances. Plasma cell differentiation is a frequent finding, and in some cases may be very prominent. All cases have a variable number of large transformed cells, but these are usually 
distributed within the small cell infiltrate. When large neoplastic cells are present in sheets, the diagnosis of an associated diffuse large B-cell lymphoma (DLBCL) should be made.

Features that help to distinguish MALT lymphoma from reactive infiltrates include the presence of a dense infiltrate of monotonous B-cells (identified by staining for CD20 or another B-cell marker) extending away from lymphoid follicles with a poorly demarcated border, the presence of cytological atypia and the finding of Dutcher bodies. Lymphoepithelial lesions are characteristic of lymphoma and are not commonly seen in reactive infiltrates. Staining for CD43 may be helpful in determining the neoplastic nature of the infiltrate as normal B-cells are negative and the antigen is frequently expressed in MALT lymphoma, but is also present on cells of B-cell chronic lymphocytic leukaemia/small lymphocytic lymphoma and mantle cell lymphoma.

Immunohistochemistry is used to distinguish MALT lymphoma from other non-Hodgkin lymphomas. Staining for CD20 or another pan B-cell antigen confirms the B-cell nature of the infiltrate. Although a few gastric MALT lymphomas stain for CD5, positive staining is more characteristic for B-cell chronic lymphocytic leukaemia/small lymphocytic lymphoma, which also express CD23, and mantle cell lymphoma which coexpresses cyclin D1. A stain for cytokeratin may help to identify lymphoepithelial lesions and a stain for follicular dendritic cells (eg, anti-CD21) will identify indistinct lymphoid follicles.

Where large cells are present, immunohistochemistry to distinguish neoplastic cells from residual germinal centre centroblasts should be used (antibodies to CD10 and bcl-6). Staining for bcl-2 protein is helpful as reactive germinal centre cells are negative and neoplastic blasts are usually positive. Staining for Ki67 may help in identifying large cell components.

Identification of light chain expression by immunohistochemistry or in situ hybridisation may help confirm the diagnosis of lymphoma but is frequently difficult to assess in small mucosal biopsies.

The presence of Helicobacter pylori should be assessed using an appropriate stain (see Helicobacter pylori section).

A confident diagnosis of gastric MALT lymphoma can be expressed using the Wotherspoon score. ${ }^{7}$

\section{Molecular investigations}

\section{Recommendations}

- Demonstration of monoclonality by PCR analysis of the rearranged immunoglobulin genes using the BIOMED-2 protocols is not a prerequisite for the diagnosis of gastric MALT Iymphoma.

- Testing for translocation $t(11 ; 18)$ should be considered at diagnosis. During post-treatment follow-up routine clonality analysis is not recommended.

\section{Comment}

For diagnostic biopsies, clonality analysis of the rearranged immunoglobulin genes by PCR may help in a diagnosis of MALT lymphoma when histological and immunophenotypic features induce suspicious but not diagnostic. ${ }^{8}$ For follow-up biopsies after treatment, the tumour clone may be detectable by PCR in $\sim 50 \%$ of cases in the absence of any macroscopic and histological evidence of lymphoma. ${ }^{9-14}$ Although the monoclonality disappears with time in some cases, it is persistently present in a high proportion $(\sim 40 \%)$ of cases, and the basal lymphoid aggregates are the source of the clonal B-cells. ${ }^{9} 11-14$ Independent studies of large cohorts with long follow-up show that cases with persistent monoclonality were associated with only a slightly higher risk of lymphoma relapse than those without persistent monoclonality. ${ }^{11-16}$ Thus, beyond clinical trials or a research setting, the current evidence does not support a significant role for clonality analysis in routine posttreatment follow-up of gastric MALT lymphoma. For clonality analysis, use of the standardised BIOMED-2 PCR protocols and a modified strategy as proposed by Liu et al are highly recommended. ${ }^{17} 18$

Translocation $\mathrm{t}(11 ; 18)$ ( $\mathrm{q} 21 ; \mathrm{q} 21)$ fuses the N-terminus of the API2 gene to the C-terminus of the MALT1 gene and generates a functional API2-MALT1 fusion product ${ }^{19}{ }^{20}$, which develops the ability to activate the nuclear factor- $\kappa \mathrm{B}(\mathrm{NF}-\kappa \mathrm{B})$ pathway. ${ }^{21}$ The translocation is specifically associated with the MALT lymphoma entity, but occurs at remarkably variable incidences in different anatomical sites. ${ }^{22}$ In gastric MALT lymphoma, $\mathrm{t}(11 ; 18)$ (q21;q21) is found in $25 \%$ of cases, more frequent in cases at stage IIE or above than those at stage IE. ${ }^{23-28}$ Independent retrospective studies from several centres demonstrate that $\mathrm{t}(11 ; 18)$ (q21; $\mathrm{q} 21)$ is seen in $47 \%$ and $68 \%$ of gastric MALT lymphomas at stage IE and stage IIE or above, respectively, which do not respond to $H$ pylori eradication. ${ }^{12} 13 \quad 28-33$ In contrast, the translocation is only observed in $3 \%$ of gastric MALT lymphomas that respond to $H$ pylori eradication, and these translocation-positive cases often show a late response and/or lymphoma relapse during follow-up. ${ }^{33}$ Thus, $t(11 ; 18)$ (q21;q21) is a strong predictor of the response of gastric MALT lymphoma to $H$ pylori eradication. In addition, $\mathrm{t}(11 ; 18)(\mathrm{q} 21 ; \mathrm{q} 21)$ was significantly associated with treatment failure of single oral alkylating agents (chlorambucil or cyclophosphamide), ${ }^{34}$ but did not predict the response to treatment with the nucleotide analogue cladribine $(2 \mathrm{CdA})^{35}$ or the anti-CD20 antibody rituximab. ${ }^{36}$ Despite its strong association with adverse clinical features, $t(11 ; 18)(q 21 ; q 21)$ is only rarely seen in transformed MALT lymphoma or DLBCL in patients from Western countries, ${ }^{37}{ }^{38}$ suggesting that the translocation-positive MALT lymphomas rarely undergo high-grade transformation. For the reasons discussed above, testing for $\mathrm{t}(11 ; 18)(\mathrm{q} 21 ; \mathrm{q} 21)$ at diagnosis would be valuable in guiding treatment choice. Nevertheless, $H$ pylori eradication will be initiated as the first step of treatment in $H$ pylori-positive cases irrespective of the $t(11 ; 18)$ (q21;q21) status. There is, however, no clear evidence to suggest that monitoring $\mathrm{t}(11 ; 18)$ (q21; $\mathrm{q} 21)$ during follow-up is useful in guiding clinical management.

Translocation $\mathrm{t}(11 ; 18)(\mathrm{q} 21 ; \mathrm{q} 21)$ can be detected fairly simply by interphase fluorescence in situ hybridisation (FISH) with a commercial MALT1 dual-colour break-apart probe and a API2MALT1 dual-colour dual-fusion probe, or reverse transcription-PCR (RT-PCR) of the API2-MALT1 fusion mRNA transcripts. Both methods can be applied to routine formalinfixed paraffin-embedded tissue biopsies and showed highly concordant results when appropriately performed. Interphase FISH requires small amounts of tissue (only 1-2 tissue sections), allows easy correlation with histological features and has no or a minimal risk of a false-positive result, while the RT-PCR-based detection method is highly sensitive, but requires larger amounts of tissue ( $\geq 5$ tissue sections depending on the size of the tissue biopsy) than FISH and does not permit accurate morphological correlation. Currently, there are no immunophenotypic markers 
that are sensitive and specific enough to be used as a reliable surrogate marker for $\mathrm{t}(11 ; 18)(\mathrm{q} 21 ; \mathrm{q} 21)$ and gastric MALT lymphomas that do not respond to $H$ pylori eradication. The above molecular and genetic methods should be used for the translocation detection.

Translocations $\mathrm{t}(1 ; 14)(\mathrm{p} 22 ; \mathrm{q} 32) / B C L 10-I G H, \quad \mathrm{t}(14 ; 18)$ (q32; $\mathrm{q} 21) / I G H-M A L T 1$ and $\mathrm{t}(3 ; 14)(\mathrm{p} 14 ; \mathrm{q} 32) / F O X P 1-I G H$ are only rarely found in gastric MALT lymphoma, ${ }^{24} 39-42$ and the clinical significance of these translocations remains to be investigated. Chromosomal trisomies 3, 12 and 18 are frequently seen in $t$ $(11 ; 18)(q 21 ; q 21)$-negative MALT lymphomas. Currently, there is no clear evidence to suggest that detection of these chromosomal numerical changes is valuable in guiding clinical management.

Clinical diagnosis and staging

Endoscopic diagnosis

\section{Recommendation}

A gastric mapping procedure with a sufficient number of biopsies from macroscopic lesions and normal mucosa should be performed in the case of suspected or diagnosed gastric MALT Iymphoma to allow an accurate diagnosis and typing of the lymphoma.

\section{Comment}

A minimum of 10 biopsy samples should be taken from visible lesions. In addition, biopsies should also be taken from macroscopically normal mucosa. In cases where gastric MALT lymphoma is suspected but insufficient or inadequate initial biopsy materials have been received, a second endoscopy could be necessary. H pylori eradication therapy should not be started until the results of the reference pathologist are available.

A gastric mapping procedure should also be performed to assess subsequent treatment response (regarding lymphoma regression) to $H$ pylori eradication, radiation or chemotherapy.

\section{Staging}

\section{Recommendation}

Staging classification should be based on the Ann Arbor staging system with its modifications by Musshoff and Radaszkiewicz. In addition, staging can be done according to the Paris staging system (TNMB).

\section{Comment}

Over time, the staging of extranodal lymphomas based on the Ann Arbor classification has been modified many times to make its application to lymphomas of the gastrointestinal tract possible. Musshoff introduced the first modification in 1977 that differentiated stage IIE lymphomas with involvement of neighbouring lymph nodes (II1E) and distant lymph nodes (II2E). ${ }^{43}$ In 1992, differentiation of stage IE was introduced: mucosa and submucosa (I1E) versus muscularis propria to serosa (I2E) involvement. ${ }^{44}$ The Blackledge staging system known as the
'Lugano staging system' proposed in 1994 was mainly based on radiological findings. ${ }^{45}$ Many systems have been proposed before introduction of endoscopic ultrasound in clinical routine. These systems do not describe the depth of infiltration of the gastric wall that is highly predictive for the MALT lymphoma response to anti-Helicobacter treatement. For the specific diagnostic requirements of gastrointestinal lymphomas, a modification of the existing TNM system was implemented by the EGILS group (table 1). ${ }^{46}$ This Paris staging system (TNMB) adequately describes the three most important characteristics of gastrointestinal lymphomas: (1) depth of lymphoma infiltration, ${ }^{47}(2)$ lymph node infiltration and (3) lymphoma spread. However, this system has not been validated by prospective studies yet.

\section{Recommendations}

- If a diagnosis of gastric MALT lymphoma is established a staging procedure to assess the dissemination of the lymphoma (clinical stage) is mandatory.

- Initial staging examinations must include: physical examination (including peripheral lymph nodes and Waldeyer's ring), routine laboratory parameters (complete blood count, lactate dehydrogenase (LDH) and $\beta$-2-microglobulin levels, serum protein immunofixation, HIV, hepatitis C virus (HCV) and hepaptitis $B$ virus (HBV) serology) and abdominal, pelvic and thoracic CT scan.

- Endoscopic ultrasound should be performed in initial staging. Bone marrow biopsy should be done in the case of failure of lymphoma regression after $H$ pylori eradication and before initiating oncological treatment. lleocolonoscopy should be considered.

\section{Comment}

As the stage of disease is one of the two most important prognostic factors and therapeutically determinant, an adequate staging procedure has to be performed in every case. ${ }^{44} 4849$

Ultrasound of the abdomen and lymph nodes seems unnecessary with the use of corresponding CT scans.

Endoscopic ultrasound (EUS) is the only technique that visualises the different layers of the gastric wall and perigastric lymph node involvement. Therefore, it has the potential to differentiate stages I1E, I2E and IIIE and T1-4, N0/1, respectively (table 1 ). This differentiation is of clear prognostic value. $^{50-58}$

Table 1 Staging systems for gastrointestinal lymphomas

\begin{tabular}{|c|c|c|}
\hline $\begin{array}{l}\text { Ann Arbor system, } \\
\text { modified* }^{*}\end{array}$ & $\begin{array}{l}\text { Paris staging } \\
\text { system } †\end{array}$ & Spreading of lymphoma \\
\hline I1E & TI NOMO & Mucosa, submucosa \\
\hline I2E & T2NOMO & Muscularis propria, subserosa \\
\hline I2E & T3NOMO & Serosa penetration \\
\hline I2E & T4NOMO & $\begin{array}{l}\text { Per continuitatem infiltration of } \\
\text { neighbouring organs }\end{array}$ \\
\hline II1E & $\mathrm{T} 1-4 \mathrm{~N} 1 \mathrm{M} 0$ & $\begin{array}{l}\text { Regional lymph nodes } \\
\text { (compartment I+II) }\end{array}$ \\
\hline II2E & $\mathrm{T} 1-4 \mathrm{~N} 2 \mathrm{MO}$ & Intra-abdominal distant lymph nodes \\
\hline IIIE & $\mathrm{T} 1-4 \mathrm{~N} 3 \mathrm{M} 0$ & Extra-abdominal lymph nodes \\
\hline \multirow[t]{2}{*}{ IV } & $\mathrm{T} 1-4 \mathrm{~N} 0-3 \mathrm{M} 1$ & $\begin{array}{l}\text { Diffuse or disseminated infiltration of } \\
\text { distant or extra-gastrointestinal organs }\end{array}$ \\
\hline & B1 & Bone marrow \\
\hline
\end{tabular}

${ }^{*}$ Modified by Musshoff ${ }^{43}$ and Radaszkiewicz et al. ${ }^{44}$

†Ruskoné-Fourmestraux et al. ${ }^{46}$ 
A bone marrow biopsy is recommended when no lymphoma regression is seen after an adequate interval, following $H$ pylori eradication. Before initiating locoregional treatment (ie, radiation), disseminated disease needing systemic chemotherapy has to be excluded. ${ }^{59}$

In patients with gastric MALT lymphoma, multifocal involvement of the gastrointestinal tract may occur occasionally. ${ }^{50-61}$ There are very few systematic data on the involvement of the small intestine and colon. ${ }^{62}$ Therefore, a general recommendation on small intestine diagnostics and ileocolonoscopy cannot be given, although we tend to favour the latter.

\section{HELICOBACTER PYLORI}

\section{Recommendation}

- $H$ pylori infection causes most cases of gastric MALT lymphoma. Therefore, diagnosis and treatment of $H$ pylori infection is the first step in the management of gastric MALT lymphoma independent of the stage of disease.

\section{Comment}

There is now overwhelming evidence that $H$ pylori infection causes gastric MALT lymphoma, and a systematic review of published series has shown $H$ pylori infection in $88.8 \%$ of 2000 patients with gastric MALT lymphoma. ${ }^{63}$ Hill's criteria of causality have been fulfilled, including the healing of the lesions after $H$ pylori eradication, even if double-blind randomised clinical trials have not been carried out for ethical reasons. ${ }^{8}$

A minority of gastric MALT lymphomas are caused by a different Helicobacter species named ' $H$ heilmannii'. This is not a validated species and corresponds to a group of different microrganisms which are very fastidious to grow and, consequently, difficult to differentiate: $H$ felis, $H$ bizzozeroni, $H$ salomonis, $H$ suis and $H$ bovis. ${ }^{64}{ }^{65} \mathrm{~A}$ small minority of gastric MALT lymphomas appears to be unrelated to any of these microrganisms and are probably due to as yet unidentified causes.

There is evidence that $H$ pylori eradication cures gastric MALT lymphoma only in stage IE and, to a much lesser percentage, in stage II1E. Nevertheless it is preferable to eradicate $H$ pylori in all cases as it is a trigger of the immune response.

\section{Recommendation}

- Histology is the first diagnostic choice for $H$ pylori infection since it is the best diagnostic tool in the case of gastric MALT lymphoma. Additionally, according to the specific situation, different tests can be used.

\section{Comment}

Histology is performed to establish the diagnosis of gastric MALT lymphoma but also allows the diagnosis of $H$ pylori infection. The usual limitations of histology for $H$ pylori diagnosis are the limited number of biopsies examined and their quality, as well as the expertise of the pathologists and the time devoted to the diagnosis. Two studies have shown high interobserver variability in the results. ${ }^{66} 67$
In gastric MALT lymphoma diagnosis, these limitations do not exist. In order to obtain an accurate diagnosis of lymphoma, a large number of biopsies are examined and, in many cases, the slides are reviewed by a group of expert pathologists who devote time to reach a consensus. It was shown that the sensitivity of histology for $H$ pylori diagnosis increased with the number of biopsies, up to $95 \%$ with five biopsies. ${ }^{68}$ Histology is at its optimum in this context.

For histological assessment of $H$ pylori, biopsies from the gastric antrum and body have to be taken from an area away from mucosal lesions. Proton pump inhibitor (PPI) treatment has to be withdrawn at least 2 weeks before endoscopy because it may give a false-negative result with all the $H$. pylori diagnostic tests except serology. ${ }^{69} 70$ Besides $H$ pylori, histological examination also allows the detection of $H$ heilmannii.

These organisms are usually detectable on H\&E-stained sections. Special stains such as Giemsa, immunohistochemistry or FISH increase the sensitivity of $H$ pylori detection. These are advised, particularly in the case of a scanty bacterial load or an apparent absence of infection on routinely stained slides. ${ }^{71}$

In the case of positive histology, culture is recommended as the second diagnostic test, if another endoscopy is needed for diagnosis or gastric mapping. In gastric MALT lymphoma, culture has a lower sensitivity than histology even if performed under good conditions, ${ }^{72}$ but gives information on the antimicrobial susceptibility especially for the key antibiotic-that is, clarithromycin.

In the case of negative histology, serology is recommended. ${ }^{72} 73$ Consumption of PPIs or antibiotics can suppress the infection but does not lead to eradication, ${ }^{69707475}$ and serology will be the only diagnostic test to be positive in such cases. After $H$ pylori eradication, the antibodies remain present for weeks and often months. Serology, therefore, also allows detection of a recently cured infection.

\section{Recommendation}

- PPI+clarithromycin-based triple therapy with either amoxicillin or metronidazole is the first choice for $H$ pylori eradication. In case of failure, bismuth-based quadruple therapy is recommended.

\section{Comment}

Most of the consensus conferences held around the world in recent years have recommended the use of a PPI+clarithromycinbased triple therapy composed of a double dose of a PPI plus two antibiotics: clarithromycin and amoxicillin or metronidazole. ${ }^{76}$

However, because of an increasing clarithromycin resistance, an important drop in efficacy has been observed leading to the recommendation either to avoid this drug or to test its susceptibility before using it in the areas where the incidence of clarithromycin resistance is $>15 \% .^{76} 77$

The length of treatment is debatable. However, the data from meta-analyses show better results if the treatment is given for 14 days compared with 7 days, while the difference is not significant between 7 and 10 days. ${ }^{76}$ A recent pooled data analysis of 1271 patients with gastric MALT lymphoma from 34 studies has shown a successful eradication rate of $91 \%$ after first-line treatment which was extended to $98 \%$ after more attempts. ${ }^{78}$

A meta-analysis of bismuth-based quadruple therapy containing a PPI, bismuth, tetracycline and metronidazole 
shows that the best results are obtained when the four drugs are given for 10-14 days. Even in areas with a high prevalence of metronidazole resistance, the quadruple regimen eradicated $>85 \%$ of $H$ pylori strains. ${ }^{79}$ Other treatments comprising PPI-tetracycline-metronidazole or PPI-amoxicillin-rifabutin have been proposed, but the latter has toxic effects and should be considered as the last option. It should be mentioned, however, that in some countries bismuth compounds are currently not available.

\section{Recommendation}

The outcome of $H$ pylori eradication therapy should be checked by urea breath test at least 6 weeks after eradication therapy and at least 2 weeks after withdrawal of PPI medication.

\section{Comment}

To assess the effective $H$ pylori eradication the method universally accepted is the urea breath test. ${ }^{76}$

To assess MALT lymphoma remission, a first endoscopy is performed 3-6 months after completion of antibacterial treatment, thus allowing for checking of the $H$ pylori status histologically at the same time. Culture and susceptibility testing are particularly recommended to guide further treatment in the case of a resistant strain indicated by a persistent positive breath test.

\section{Recommendation}

H pylori-negative patients with gastric MALT lymphoma can also undergo anti-H pylori treatment.

\section{Comment}

Prescription of an eradication treatment has also been advised in cases of $H$ pylori-negative gastric MALT lymphoma. The arguments to support this are that $H$ pylori may have been missed by the diagnostic tests, or that another Helicobacter, $H$ heilmannii, may be the cause. ${ }^{65}$ Some $H$ pylori-negative gastric MALT lymphomas have been reported to respond with complete lymphoma remission after exclusive anti-H pylori treatment, 8081 but these were only anectodal cases. A recent review of the published cases shows that out of 72 patients, 14 (19\%) responded to the treatment. ${ }^{82}$

\section{TREATMENT}

\section{Recommendation}

- The first-line treatment of all gastric MALT lymphomas is $H$. pylori eradication therapy independent of the stage. Nevertheless, the staging procedure has to be performed before starting eradication therapy. Patients who respond to eradication therapy (lymphoma regression) should not receive any other treatment.

\section{Comment}

In patients with localised disease $H$ pylori eradication leads to complete lymphoma remission in some $60-90 \%$ of cases. $^{8} 105254-5783-86$
In a recent systematic review of the literature analysing data from 32 studies including 1408 patients, the gastric MALT lymphoma remission rate was $77.5 \% .{ }^{63}$ It was significantly higher in patients with stage IE than stage II1E lymphoma (78.4\% vs $55.6 \%$ ). Neoplasia confined to the mucosa regressed more frequently $(82.2 \%$ of cases) than those with a deeper invasion of the gastric wall (54\%). This complete remission is maintained for years in most cases, and offers a chance of cure. $^{10} 12 \quad 13 \quad 8587-91$ Relapses have been described in $<10 \%$ of patients $(7.2 \%$ in the review of Zullo et al) and may be occasionally associated with $H$ pylori recrudescence/reinfection. ${ }^{92}$ Should the presence of $H$ pylori be found again with or without relapsing lymphoma, further eradication therapy is indicated.

Some patients show histologically identified residual circumscribed lymphoid aggregates after successful $H$ pylori eradication and normalisation of the endoscopic findings. The histological changes regress during the second year of follow-up in $32 \%$ of cases and remain stable in another $62 \%$. They do not need additional treatment and can be managed by a 'watch and wait' strategy unless progression or recurrence of endoscopic lesions can be demonstrated. ${ }^{93}$

In patients responding to $H$ pylori eradication (either complete or partial remission), treatment with chlorambucil did not result in a superior disease control when compared with a 'watch and wait' strategy in a recently reported randomised trial. ${ }^{94}$

There are specific situations in which treatment with antibiotics will probably not result in a good response of the lymphoma. $H$ pylori-negative lymphomas 5455 , t(11;18)-positive lymphomas ${ }^{30} 95$ and those with lymph node involvement will hardly respond to antibiotics. ${ }^{55}$ Patients with gastric MALT lymphoma refractory to $H$ pylori eradication and persistent endoscopic lesions as well as those with disseminated or bulky disease will require further local or systemic treatment.

\section{Recommendation}

Surgery nowadays is restricted to the treatment of rare complications such as perforation or bleeding that cannot be controlled endoscopically.

\section{Comment}

In the 'pre-Helicobacter pylori era', surgery has been the main therapeutic intervention. It has provided very good results for localised disease, with long-term survival for between $75 \%$ and $97 \%$ of patients. ${ }^{48} 60$ 96-101 Despite these excellent data, the major limitation of total gastrectomy to control this multifocal disease is that it has life-long nutritional and metabolic consequences. In recent years a few prospective studies reported no disadvantage with the organ-preserving treatment. ${ }^{61} 102103$ For these reasons, surgery nowadays is restricted to the treatment of rare complications such as perforation or bleeding that cannot be controlled endoscopically.

\section{Recommendation}

Both radiotherapy and chemotherapy have a curative potential in localised gastric MALT Iymphoma. There is no recommendation in favour of one of these two modalities. If clinical trials are available, patients should be included. 


\section{Comment}

The curative potential of radiation and chemotherapy as well as of diverse combined treatment modalities in gastric MALT lymphoma was shown in retrospective studies. ${ }^{60} 83$ 104-107 There is no doubt that disseminated disease needs systemic chemotherapy. A pooled data analysis assessing the efficacy of different oncological therapeutic approaches to treat limited disease gastric MALT lymphoma unresponsive to $H$ pylori eradication showed a slightly higher remission rate following radiotherapy as compared with chemotherapy (97.3\% vs $85.3 \%$; $\mathrm{p}=0.007)$, being similar to surgery $(97.3 \%$ vs $92.5 \% ; p=0.2) .{ }^{108}$ However, in the case of localised disease, there is only one study which compared surgery, radiation and chemotherapy, CHOP/ COP, suggesting a higher event-free survival with chemotherapy but no significant difference in overall survival after a median follow-up of 7.5 years (table 2). ${ }^{102}$ No data are available directly comparing radiation and chemotherapy. With respect to the high response rate of gastric MALT lymphoma to $H$ pylori eradication and its indolent course, it is difficult to conduct such studies. Nevertheless, a study on radiation versus chemotherapy following failure of $H$ pylori eradication would offer important information for treating such patients. ${ }^{109}$

\section{Radiotherapy}

\section{Recommendation}

- Radiation is effective for patients with localised gastric MALT lymphoma of stage IE-IIIE (T1-4, N0/1MOBO) that failed to respond to $H$ pylori eradication.

\section{Comment}

Concepts concerning radiotherapy in gastric MALT lymphoma have changed significantly over time. Knowledge concerning the pattern of spread of gastric MALT lymphoma has increased through surgical series and the use of modern radiological examinations. Low-grade MALT lymphoma tends to be confined to the gastric wall. In contrast to MALT lymphomas of other origin, distant relapses of gastric MALT lymphoma rarely occur (0-5\%). ${ }^{59} 110111$ Lymph node involvement may be observed, but in the vast majority only restricted to the perigastric nodes (stage II1E or T1-4, N+). ${ }^{6} 60112$ Therefore, the target volume for radiotherapy should be limited to the stomach and the perigastric nodes. In parallel, radiation doses have been reduced over decades.

MALT lymphomas have been reported to be highly sensitive to radiation, ${ }^{99} 104113114$ and treatment is potentially curative in localised stage IE and II1E (5-year event-free survival rates $\sim 80-90 \%$ ). These studies used relatively high doses of $36 \mathrm{~Gy}$ up to 45 Gy (mostly $40 \mathrm{~Gy}$ ) or a multimodality treatment approach. However, in several small series using lower radiation doses of $\leq 30 \mathrm{~Gy}$, response rates between $93 \%$ and $100 \%$ and overall survival rates between $96 \%$ and $100 \%$ based on a median follow-up of 3.3-7.2 years were reported. ${ }^{103} 115-117$

If radiotherapy is indicated for limited stage low-grade gastric MALT lymphoma, radiation doses of 30-40 Gy in 15-20 fractions are actually proposed. Currently, studies are being performed evaluating the possibility of lowering the radiation dose to $\sim 30$ Gy. It is recommended to treat patients with such protocols. ${ }^{118} 119$ Using 3D conformal radiotherapy and intensity- modulated radiation therapy (IMRT) enables the kidney dose to be decreased compared with parallel opposed beams. ${ }^{120}$ In addition, stomach distension can be minimised by treating the patient in a fasting state. As always the dose to normal tissues should be kept as low as reasonably achievable; the dose to the kidneys should be limited to $<20$ Gy (for at least two-thirds of one kidney) and to $<30$ Gy mean liver dose. ${ }^{121}$

The side effects of irradiation strongly depend on the radiation field and dose. Acute side effects of radiation to the stomach consist mainly of transient anorexia, nausea and vomiting. These complaints can usually be adequately treated with antiemetics and a PPI. Late effects of radiotherapy to the stomach and perigastric nodes of 30-40 Gy in 15-20 fractions using modern radiation techniques are expected to be minimal.

Hence radiotherapy is effective and safe.

\section{Chemotherapy and immunotherapy}

\section{Recommendation}

Chemotherapy and immunotherapy are effective in patients with gastric MALT lymphoma of all stages.

\section{Comment}

Different types of chemotherapy and immunotherapy are effective in the treatment of gastric (and non-gastric) MALT lymphoma with both limited and advanced stages of disease. However, the available data come from only a few phase II studies with a limited number of patients and relatively short duration of follow-up (table 2). Therefore, they cannot provide consistent evidence, and no standard chemotherapy has been defined so far.

Alkylating agents as a sole treatment are well tolerated and effective, with $75 \%$ of patients showing a complete remission and $28 \%$ showing relapsing disease, ${ }^{122}$ but they seem to lack activity in $\mathrm{t}(11 ; 18)$ (q21;q21)-positive lymphomas. ${ }^{34}$ In $\mathrm{t}(11 ; 18)$ (q21;q21)-negative patients, chlorambucil might be used, while 2CdA exerts activity irrespective of $t(11 ; 18)(q 21 ; q 21)$ status and is the drug with the best documented long-term activity in gastric MALT lymphoma, albeit in a small number of patients. ${ }^{35}$ However, there is concern regarding the risk of developing myelodysplasia. ${ }^{123}$ Outside of clinical trials, cyclophosphamide, vincristine and prednisolone might also be used. Other drugs such as oxaliplatin, bortezomib or various combinations including mitoxantrone, chlorambucil and dexamethasone have suggested activity, but the number of patients tested so far is simply too small to justify the use outside of clinical trials. ${ }^{124}$ The use of rituximab has not been clearly defined in MALT lymphoma, but despite its potential palliative activity the rate of complete remissions is relatively low (29-46\%). Combination with $\mathrm{CHOP}$ is relatively toxic, and should be discouraged in this indolent disease. Combination with fludarabine or $2 \mathrm{CdA}$ has been tested, but has not been shown to be more effective than the nucleosides alone. ${ }^{36} 102123$ 125-128 129 Rituximab and chlorambucil produced $100 \%$ responses in 13 patients with $t(11 ; 18)$ positive gastric lymphomas. ${ }^{130}$ The combination of rituximab and flexible doses of fludarabine has provided sustained responses in $100 \%$ of 10 patients, with acceptable toxicity. ${ }^{131}$ The treatment response occurred in both positive and negative $t$ $(11 ; 18)$ lymphomas. 


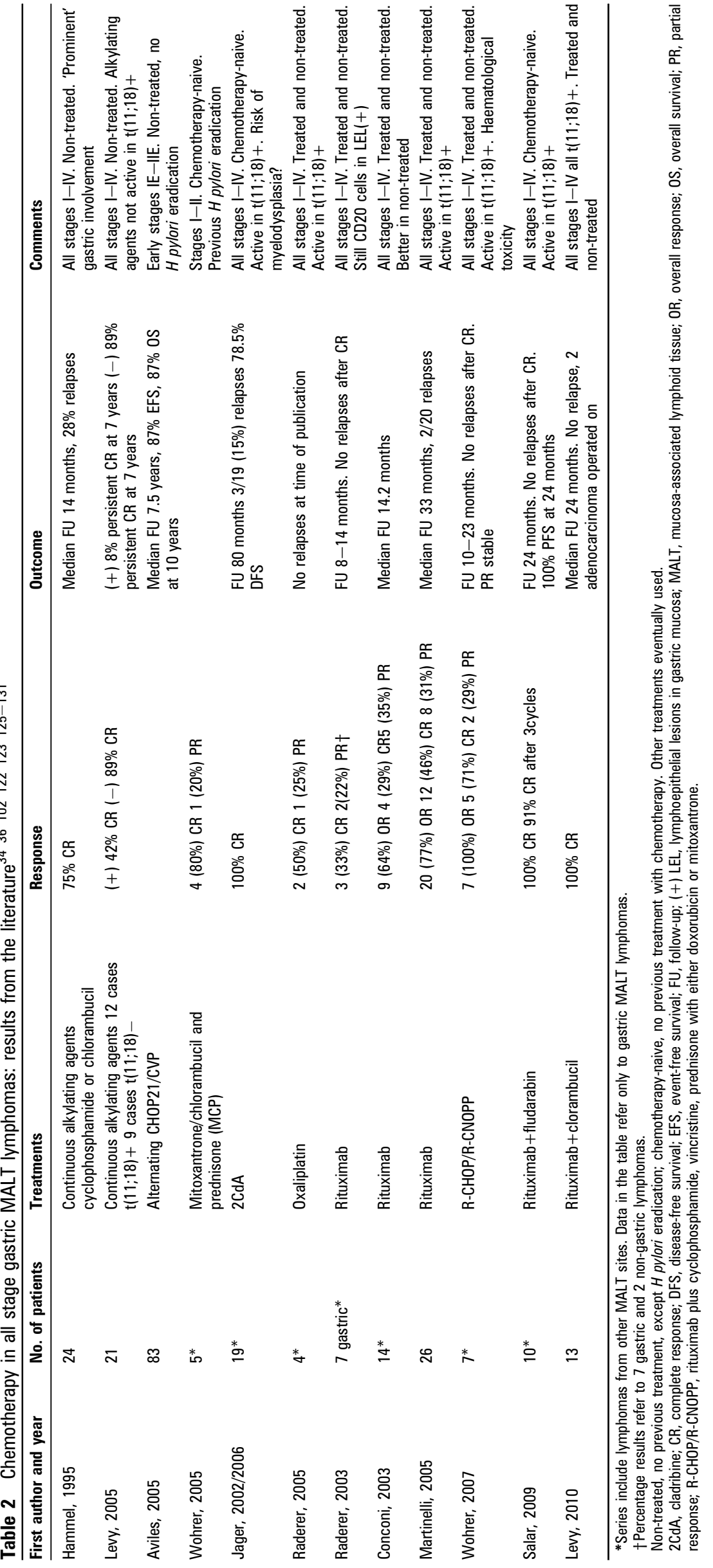




\section{RESPONSE AND FOLLOW-UP}

\section{Post-treatment evaluation}

Response is defined according to the well-accepted multidisciplinary oncological criteria. Histological evaluation of posttreatment biopsies should be performed in the context of reviewing previous biopsies and requires assessment of the cellular infiltrate, lymphoepithelial lesions and stromal changes. Wotherspoon's score, ${ }^{7}$ recommended for initial diagnosis, is no longer considered adequate for response assessment during follow-up. The system proposed by GELA (Groupe d'Etude des Lymphomes de l'Adult), which has good interobserver concordance, is recommended as it provides information on the evolving type and change in an individual case. ${ }^{132}$ In this system, four morphological categories are identified: complete histological response (CR), probable minimal residual disease (pMRD), responding residual disease (rRD) and no change (NC) (table 3).

\section{Treatment response}

Complete remission (CR) is defined as no macroscopic findings of lymphoma and negative histology (CR or pMRD) in two subsequent follow-up investigations.

Partial remission (PR) is defined as normalisation or reduction of macroscopic findings, histological signs of lymphoma regression ( $\mathrm{rRD}$ ) and no signs of progressive disease.

Stable disease (SD) is characterised by unmodified macroscopy and/or unmodified histology (NC).

Progressive disease (PD) is defined by worsening of macroscopic findings or dissemination of gastric MALT lymphoma, or transformation into DLBCL.

Relapse is defined as persistent histologically confirmed lymphoma after a complete remission was documented.

\section{Recommendations}

A first evaluation of lymphoma regression should be performed 3-6 months after completion of treatment. Further follow-up should be performed every 4-6 months thereafter until complete remission of lymphoma (clinical and histological (GELA: CR or pMRD) is documented.

- Gastroscopy with multiple biopsies (mapping-see Diagnosis section) has to be performed. Additionally, the initial sites of lymphoma involvement should be checked by appropriate methods.

\section{Comment}

Once eradication is documented (see Helicobacter pylori section), the follow-up of gastric MALT lymphoma is usually restricted to endoscopy with biopsy mapping (see Endoscopic diagnosis section). Whatever the mapping procedure adopted at initial staging, it is important to keep the same protocol during the follow-up endoscopy, in order to allow a proper histological comparison. EUS is, therefore, not generally recommended in this context. ${ }^{133-136}$

\section{Comment}

The importance of evaluating the lymphoma response after effective $H$ pylori eradication (see Helicobacter pylori section) has to be emphasised again. Complete remission is obtained usually within 6-12 months from eradication. In some cases, however, it may be delayed up to 24-72 months. $^{90}$

Two sequential follow-up gastroscopies without lymphoma are mandatory to assume complete remission regarding the possibility of a sampling error of endoscopic biopsies.

Table 3 GELA grading system for post-treatment evaluation of gastric MALT lymphoma (Copie-Bergman et al ${ }^{132}$ with comments by the authors)

\begin{tabular}{ll}
\hline GELA category & Histology \\
\hline $\begin{array}{l}\text { Complete histological } \\
\text { response (CR) }\end{array}$ & $\begin{array}{l}\text { Total disappearance of the lymphoid } \\
\text { infiltrate with only scattered small } \\
\text { lymphocytes and plasma cells. Regressive } \\
\text { stromal changes with fibrosis and separation } \\
\text { of glands can be seen. }\end{array}$ \\
$\begin{array}{l}\text { Probable minimal residual } \\
\text { disease (pMRD) }\end{array}$ & $\begin{array}{l}\text { Small lymphoid aggregates present, usually } \\
\text { at the base of the lamina propria. Associated }\end{array}$
\end{tabular}

Clinical significance Comments

Complete remission Identification of CR may be subject to sampling 'artefact' and the designation of complete regression needs sustained absence of histological disease in the context of remission as assessed by all other means. No need for additional treatment.

disease (pMRD) stromal regressive changes are usually present.

Complete remission

Partial remission

Overt residual lymphoma with a nodular or diffuse infiltrate of neoplastic B-cells but with clear evidence of regressive stromal changes characterised by fine fibrosis and an 'empty lamina propria'.

No change (NC)
Responding residual disease (rRD)
Persistence of overt lymphoma identical to that seen at diagnosis with no morphological features to suggest response to treatment (such as stromal fibrosis).
Stable disease or progressive disease

The significance of the lymphoid aggregates is impossible to determine by morphology or immunocytochemistry, but it has been established that these nodules frequently, but not always, harbour cells with the same clonal gene rearrangement as the original lymphoma cells, consistent with the presence of a small number of residual neoplastic cells. However, no adverse prognostic significance has been demonstrated associated with this histology which is detected in early followup biopsies after Helicobacter pylori eradication of most cases undergoing subsequent complete remission. No need for additional treatment.

Comparison with the diagnostic biopsy is helpful in this context. These features are considered to indicate a partial and ongoing response. In the absence of unfavourable endoscopic results or a clinical appearances of progression, a decision about additional treatment can be postponed until after the following endoscopic assessment. Management should be individually tailored.

In the case of persisting macroscopic lesions or evidence of dissemination of the disease, oncological treatment should be proposed. If only microscopic infiltration is present, oncological treatment can be postponed up to 24 months after achievement of Helicobacter pylori eradication, after which management should be individually tailored. 


\section{Recommendations}

- Complete remission (CR) has to be confirmed in two subsequent follow-up investigations.

- Partial remission (PR) has to be clinically managed on an individual basis.

- Stable disease (SD) encompasses two clinical conditions: in the case of persisting macroscopic lesions, oncological treatment should be proposed. If only microscopic infiltration is present, oncological treatment can be postponed up to 24 months after achievement of $H$ pylori eradication.

- Progressive disease (PD): patients should receive oncological treatment.

- Relapse: if no signs of endoscopic or clinical progression are evident, a 'watch and wait' strategy can be adopted. In all other cases, oncological treatment should be offered.

Patients with persistent histological lymphoma ( $r R D$ and NC) can be managed up to 24 months by a 'watch and wait' strategy unless progression or recurrent endoscopic lesions can be demonstrated. The detection of rRD might encourage continuation of this strategy beyond 24 months before considering alternative oncological treatment. However, the "watch and wait' duration might be shorter in patients with more advanced disease stage, involvement of perigastric lymph nodes, suspected high-grade transformation lymphoma, $H$ pylori-negative status and $\mathrm{t}(11 ; 18)$ (q21; $\mathrm{q} 21)$ positivity as these cases are more frequently unresponsive to anti-Helicobacter therapy alone.

The decision to continue a 'watch and wait' follow-up or to start oncological treatment should be an individually tailored multidisciplinary decision, based on clinical, histological and molecular features, the patient's preferences and data emerging from ongoing trials. An extended 'watch and wait' period is an acceptable option as high-grade transformation is extremely rare, with a reported frequency of $<1 \%$. $^{6393}$

Patients with progressive disease or clinically/endoscopically evident relapse with positive biopsies should be offered oncological treatment.

\section{Follow-up after complete remission}

\section{Recommendation}

- If complete remission of gastric MALT lymphoma is achieved, follow-up gastroscopies with biopsies seem advisable.

\section{Comment}

The rationale for follow-up gastroscopies is based on two aspects. First, local relapses may arise. In the systematic review of published series by Zullo et al including 1408 patients, $7.2 \%$ of cases experienced lymphoma relapse, with a yearly recurrence rate of $2.2 \%{ }^{6393}$ Secondly, an elevated risk for gastric carcinoma has been reported in patients with MALT lymphoma, ${ }^{137} 138$ especially when intestinal metaplasia or dysplasia are found. ${ }^{139}$ Optimal intervals between check-ups and duration of surveillance are not yet known.

\section{Author affiliations:}

${ }^{1}$ Hôpital St Antoine, AP-HP, Department of Gastroenterology, Paris, France ${ }^{2}$ Medizinische Klinik II, Klinikum Aschaffenburg, Akademisches Lehrkrankenhaus der Universität Würzburg, Aschaffenburg, Germany
${ }^{3}$ The Netherlands Cancer Institute, Department of Radiotherapy, Amsterdam, The Netherlands

${ }^{4}$ The Netherlands Cancer Institute-Antoni van Leeuwenhoek Hospital, Departments of Gastroenterology and Medical Oncology, Amsterdam, The Netherlands

${ }^{5}$ Division of Molecular Histopathology, Department of Pathology, University of Cambridge, Cambridge, UK

${ }^{6}$ INSERM U853, Université Victor Segalen Bordeaux 2, Bordeaux Cedex, France ${ }^{7}$ Department of Internal Medicine, IRYCIS, Hospital Universitario Ramón y Cajal, Madrid, Spain

${ }^{8}$ Department of Internal Medicine I, Division of Oncology, Medical University of Vienna, Austria

${ }^{9}$ Fondazione Poliambulanza, Department of Histopathology, Brescia, Italy

${ }^{10}$ The Royal Marsden Hospital, Department of Histopathology, London, UK

\section{Competing interests None.}

Contributors Additional participants of the EGILS (European Gastro-Intestinal Lymphoma Study Group) consensus conferences who have contributed to this manuscript are: B Streubel (Medical University of Vienna, Austria). P Cervera, B Fabiani, C Hennequin, C Thieblemont (Hôpital St Antoine, Hôpital St Louis, AP-HP, Paris, France). C Copie-Bergman, JC Delchier, M Levy (INSERM U955, AP-HP, hôpital Henri Mondor, Créteil, France). A de Mascarel , P Lehours (INSERM U853, CHU, Bordeaux, France). T Matysiak (CHU Nantes, France). A Neubauer, T Wundish (Philipps-Universität Marburg, Germany). C Thiede (Universitätsklinikum Carl Gustav Carus, Dresden, Germany). N Willich (University hospitals, Munster, Germany). M D'Elios (University of Florence, Italy). A Ferreri, M Ponzoni(San Raffaele scientific Institute, Milano, Italy). JP De Boer, D De Jong (The Netherlands Cancer Institute, Amsterdam, The Netherlands). E Zucca (Oncology Institute of Southern Switzerland, IELSG, Ospedale San Giovanni, Bellinzona, Switzerland). P Isaacson (London, UK).

Provenance and peer review Not commissioned; externally peer reviewed.

\section{REFERENCES}

1. Isaacson PG, Spencer J, Wright $\mathrm{DH}$. Classifying primary gut lymphomas. Lancet 1988;2:1148-9.

2. Isaacson PG. The MALT lymphoma concept updated. Ann Oncol 1995:6:319-20.

3. Swerdlow SH, Campo E, Seto M, et al. Mantle cell lymphoma. In: WHO Classification of Tumours of Haematopoietic and Lymphoid Tissues. Lyon: IARC, 2008:229-32.

4. Isaacson PG. Gastrointestinal lymphomas of T- and B-cell types. Mod Pathol 1999;12:151-8.

5. Wotherspoon AC, Doglioni C, Isaacson PG. Low-grade gastric B-cell lymphoma of mucosa-associated lymphoid tissue (MALT): a multifocal disease. Histopathology 1992:20:29-34.

6. Stolte $\mathbf{M}$, Bayerdorffer $\mathrm{E}$, Morgner $\mathrm{A}$, et al. Helicobacter and gastric MALT lymphoma. Gut 2002;50(Suppl 3):Ill19-24.

7. Wotherspoon AC, Doglioni $\mathrm{C}$, de Boni $\mathrm{M}$, et al. Antibiotic treatment for low-grade gastric MALT lymphoma. Lancet 1994;343:1503.

8. Wotherspoon AC, Doglioni C, Diss TC, et al. Regression of primary low-grade Bcell gastric lymphoma of mucosa- associated lymphoid tissue type after eradication of Helicobacter pylori. Lancet 1993;342:575-7.

9. Thiede C, Wundisch T, Alpen B, et al. Long-term persistence of monoclonal B-cells after cure of Helicobacter pylori infection and complete histologic remission in gastric mucosa-associated lymphoid tissue B-cell lymphoma. J Clin Oncol 2001;19:1600-9.

10. Savio A, Franzin G, Wotherspoon AC, et al. Diagnosis and posttreatment follow-up of Helicobacter pylori-positive gastric lymphoma of mucosa-associated lymphoid tissue: histology, polymerase chain reaction, or both? Blood 1996;87:1255-60.

11. Bertoni F, Conconi A, Capella C et al. Molecular follow-up in gastric mucosaassociated lymphoid tissue lymphomas: early analysis of the LY03 cooperative trial. Blood 2002;99:2541-4.

12. Montalban C, Santon A, Redondo C, et al. Long-term persistence of molecular disease after histological remission in low-grade gastric MALT Iymphoma treated with $\mathrm{H}$. pylori eradication. Lack of association with translocation $\mathrm{t}(11 ; 18)$ : a 10-yea updated follow-up of a prospective study. Ann Oncol 2005;16:1539-44.

13. Wundisch T, Thiede C, Morgner A, et al. Long-term follow-up of gastric MALT lymphoma after Helicobacter pylori eradication. J Clin Oncol 2005:23:8018-24.

14. Noy A, Yahalom J, Zaretsky L, et al. Gastric mucosa-associated lymphoid tissue lymphoma detected by clonotypic polymerase chain reaction despite continuous pathologic remission induced by involved-field radiotherapy. J Clin Oncol 2005;23:3768-72

15. Nakamura $\mathbf{T}$, Inagaki $H$, Seto $M$, et al. Gastric low-grade B-cell MALT lymphoma: treatment, response, and genetic alteration. J Gastroenterol 2003:38:921-9.

16. Santon A, Garcia-Cosio M, Bellosillo B, et al. Persistent monoclonality after histological remission in gastric mucosa-associated lymphoid tissue lymphoma treated with chemotherapy and/or surgery: influence of $t(11 ; 18)(q 21 ; q 21)$. Leuk Lymphoma 2008;49:1516-22.

17. Liu $\mathbf{H}$, Bench AJ, Bacon CM, et al. A practical strategy for the routine use of BIOMED-2 PCR assays for detection of B- and T-cell clonality in diagnostic haematopathology. Br J Haematol 2007;138:31-43.

18. van Dongen JJ, Langerak AW, Bruggemann $M$, et al. Design and standardization of PCR primers and protocols for detection of clonal immunoglobulin and T-cell 
receptor gene recombinations in suspect lymphoproliferations: report of the BIOMED-2 Concerted Action BMH4-CT98-3936. Leukemia 2003;17:2257-317.

19. Akagi T, Motegi M, Tamura $A$, et al. A novel gene, MALT1 at 18q21, is involved in $\mathrm{t}(11 ; 18)(\mathrm{q} 21 ; \mathrm{q} 21)$ found in low-grade B-cell lymphoma of mucosa-associated lymphoid tissue. Oncogene 1999;18:5785-94.

20. Dierlamm J, Baens M, Wlodarska I, et al. The apoptosis inhibitor gene API2 and a novel $18 q$ gene, MLT, are recurrently rearranged in the $t(11 ; 18)(q 21 ; q 21)$ associated with mucosa-associated lymphoid tissue lymphomas. Blood 1999; 93:3601-9.

21. Morgan JA, Yin $Y$, Borowsky AD, et al. Breakpoints of the $t(11 ; 18)(q 21 ; q 21)$ in mucosa-associated lymphoid tissue (MALT) lymphoma lie within or near the previously undescribed gene MALT1 in chromosome 18. Cancer Res 1999:59:6205-13.

22. Isaacson PG, Du MO. MALT Iymphoma: from morphology to molecules. Nat Rev Cancer 2004:4:644-53.

23. Itoh Y, Ohtaki $\mathrm{H}, \mathrm{Ono} \mathrm{T}$, et al. A case of lymphoma-type alpha-chain disease. Acta Haematol 1991;86:107-10.

24. Murga Penas EM, Hinz K, Roser K, et al. Translocations $t(11 ; 18)(q 21 ; q 21)$ and $t$ $(14 ; 18)(q 32 ; q 21)$ are the main chromosomal abnormalities involving MLT/MALT1 in MALT Iymphomas. Leukemia 2003:17:2225-9.

25. Ye H, Liu $H$, Raderer $M$, et al. High incidence of $t(11 ; 18)(q 21 ; q 21)$ in Helicobacter pylori-negative gastric MALT Iymphoma. Blood 2003;101:2547-50.

26. Streubel B, Simonitsch-Klupp I, Mullauer L, et al. Variable frequencies of MALT lymphoma-associated genetic aberrations in MALT lymphomas of different sites. Leukemia 2004;18:1722-6.

27. Remstein ED, Dogan A, Einerson RR, et al. The incidence and anatomic site specificity of chromosomal translocations in primary extranodal marginal zone B-cell lymphoma of mucosa-associated lymphoid tissue (MALT lymphoma) in North America. Am J Surg Pathol 2006;30:1546-53

28. Nakamura S, Ye H, Bacon CM, et al. Clinical impact of genetic aberrations in gastric MALT lymphoma: a comprehensive analysis using interphase fluorescence in situ hybridisation. Gut 2007:56:1358-63.

29. Alpen B, Neubauer A, Dierlamm J, et al. Translocation $t(11 ; 18)$ absent in early gastric marginal zone B-cell lymphoma of MALT type responding to eradication of Helicobacter pylori infection. Blood 2000;95:4014-15.

30. Liu H, Ye H, Ruskone-Fourmestraux $A$, et al. $T(11 ; 18)$ is a marker for all stage gastric MALT lymphomas that will not respond to $H$. pylori eradication. Gastroenterology 2002;122:1286-94.

31. Nakamura S, Matsumoto T, Jo Y, et al. Chromosomal translocation t(11;18)(q21; q21) in gastrointestinal mucosa associated lymphoid tissue lymphoma. J Clin Pathol 2003; 56:36-42.

32. Iwano M, Okazaki K, Uchida K, et al. Characteristics of gastric B-cell lymphoma of mucosa-associated lymphoid tissue type involving multiple organs. J Gastroenterol 2004;39:739-46.

33. Yeh KH, Kuo SH, Chen LT, et al. Nuclear expression of BCL10 or nuclear factor kappa B helps predict Helicobacter pylori-independent status of low-grade gastric mucosa-associated lymphoid tissue lymphomas with or without $t(11 ; 18)(q 21 ; q 21)$. Blood 2005;106:1037-41.

34. Levy M, Copie-Bergman C, Gameiro C, et al. Prognostic value of translocation t $(11 ; 18)$ in tumoral response of low-grade gastric lymphoma of mucosa-associated lymphoid tissue type to oral chemotherapy. J Clin Oncol 2005;23:5061-6.

35. Streubel B, Ye H, Du MQ, et al. Translocation $t(11 ; 18)(q 21 ; q 21)$ is not predictive of response to chemotherapy with $2 \mathrm{CdA}$ in patients with gastric MALT Iymphoma. Oncology 2004;66:476-80

36. Martinelli G, Laszlo D, Ferreri AJ, et al. Clinical activity of rituximab in gastric marginal zone non-Hodgkin's lymphoma resistant to or not eligible for anti-Helicobacter pylori therapy. J Clin Oncol 2005;23:1979-83.

37. Remstein ED, Kurtin PJ, James CD, et al. Mucosa-associated lymphoid tissue lymphomas with $\mathrm{t}(11 ; 18)(\mathrm{q} 21 ; \mathrm{q} 21)$ and mucosa-associated lymphoid tissue lymphomas with aneuploidy develop along different pathogenetic pathways. Am J Pathol 2002:161:63-71.

38. Tan SY, Ye H, Liu $H$, et al. $t(11 ; 18)(q 21 ; q 21)$-positive transformed MALT lymphoma. Histopathology 2008;52:777-80.

39. Ye H, Liu H, Attygalle $A$, et al. Variable frequencies of $t(11 ; 18)(q 21 ; q 21)$ in MALT lymphomas of different sites: significant association with CagA strains of $\mathrm{H}$ pylori in gastric MALT Iymphoma. Blood 2003;102:1012-18.

40. Ye H, Gong L, Liu H, et al. Strong BCL10 nuclear expression identifies gastric MALT lymphomas that do not respond to $H$ pylori eradication. Gut 2006;55:137-8.

41. Goatly A, Bacon CM, Nakamura S, et al. FOXP1 abnormalities in lymphoma: translocation breakpoint mapping reveals insights into deregulated transcriptional control. Mod Pathol 2008;21:902-11.

42. Haralambieva $\mathbf{E}$, Adam $P$, Ventura $R$, et al. Genetic rearrangement of FOXP1 is predominantly detected in a subset of diffuse large B-cell lymphomas with extranodal presentation. Leukemia 2006;20:1300-3.

43. Musshoff K. [Clinical staging classification of non-Hodgkin's lymphomas (author's transl)]. Strahlentherapie 1977;153:218-21 [in German].

44. Radaszkiewicz T, Dragosics B, Bauer P. Gastrointestinal malignant lymphomas of the mucosa-associated lymphoid tissue: factors relevant to prognosis. Gastroenterology 1992;102:1628-38.

45. Rohatiner A, d'Amore F, Coiffier B, et al. Report on a workshop convened to discuss the pathological and staging classifications of gastrointestinal tract lymphoma. Ann Oncol 1994;5:397-400.
46. Ruskone-Fourmestraux A, Dragosics B, Morgner A, et al. Paris staging system for primary gastrointestinal lymphomas. Gut 2003;52:912-13.

47. Toyoda H, Nomoto $\mathrm{Y}$, li N, et al. Endosonographic images of low-grade lymphoma of mucosa-associated lymphoid tissue after radiotherapy. J Clin Gastroenterol 2001;33:237-40.

48. Cogliatti SB, Schmid U, Schumacher U, et al. Primary B-cell gastric lymphoma: a clinicopathological study of 145 patients. Gastroenterology 1991;101:1159-70.

49. Ruskone-Fourmestraux A, Aegerter P, Delmer A, et al. Primary digestive tract lymphoma: a prospective multicentric study of 91 patients. Groupe d'Etude des Lymphomes Digestifs. Gastroenterology 1993;105:1662-71.

50. Montalban C, Castrillo JM, Abraira V, et al. Gastric B-cell mucosa-associated lymphoid tissue (MALT) lymphoma. Clinicopathological study and evaluation of the prognostic factors in 143 patients. Ann Oncol 1995;6:355-62.

51. Boot $\mathbf{H}$, de Jong D, Aleman BM, et al. Gastrointestinal lymphomas-the Dutch experience. Recent Results Cancer Res 2000:156:93-8.

52. Fischbach W, Goebeler-Kolve ME, Greiner A. Diagnostic accuracy of EUS in the local staging of primary gastric lymphoma: results of a prospective, multicenter study comparing EUS with histopathologic stage. Gastrointest Endosc 2002; 56:696-700

53. Sackmann M, Morgner A, Rudolph B, et al. Regression of gastric MALT Iymphoma after eradication of Helicobacter pylori is predicted by endosonographic staging. MALT Lymphoma Study Group. Gastroenterology 1997;113:1087-90.

54. Steinbach G, Ford R, Glober G, et al. Antibiotic treatment of gastric lymphoma of mucosa-associated lymphoid tissue. An uncontrolled trial. Ann Intern Med 1999:131:88-95.

55. Ruskone-Fourmestraux A, Lavergne A, Aegerter $\mathrm{PH}$, et al. Predictive factors for regression of gastric MALT Iymphoma after anti-Helicobacter pylori treatment. Gut 2001:48:297-303.

56. Morgner A, Bayerdorffer E, Neubauer A, et al. Gastric MALT lymphoma and its relationship to Helicobacter pylori infection: management and pathogenesis of the disease. Microsc Res Tech 2000:48:349-56.

57. Bayerdorffer $\mathbf{E}$, Neubauer A, Rudolph B, et al. Regression of primary gastric lymphoma of mucosa-associated lymphoid tissue type after cure of Helicobacter pylori infection. MALT Lymphoma Study Group. Lancet 1995;345:1591-4.

58. Levy M, Copie-Bergman C, Traulle C, et al. Conservative treatment of primary gastric low-grade B-cell lymphoma of mucosa-associated lymphoid tissue: predictive factors of response and outcome. Am J Gastroenterol 2002;97:292-7.

59. Raderer M, Vorbeck F, Formanek M, et al. Importance of extensive staging in patients with mucosa-associated lymphoid tissue (MALT)-type lymphoma. Br J Cancer 2000;83:454-7.

60. Fischbach W, Dragosics B, Kolve-Goebeler ME, et al. Primary gastric B-cell lymphoma: results of a prospective multicenter study. The German-Austrian Gastrointestinal Lymphoma Study Group. Gastroenterology 2000;119:1191-202.

61. Koch P, Probst A, Berdel WE, et al. Treatment results in localized primary gastric Iymphoma: data of patients registered within the German multicenter study (GIT NHL 02/96). J Clin Oncol 2005;23:7050-9.

62. Flieger D, Keller R, May A, et al. Capsule endoscopy in gastrointestinal lymphomas. Endoscopy 2005;37:1174-80.

63. Zullo A, Hassan C, Cristofari F, et al. Effects of Helicobacter pylori eradication on early stage gastric mucosa-associated lymphoid tissue lymphoma. Clin Gastroenterol Hepatol 2010;8:105-10.

64. De Groote D, Van Doorn LJ, Van den Bulck K, et al. Detection of non-pylori Helicobacter species in "Helicobacter heilmannii"-infected humans. Helicobacter 2005; 10:398-406

65. Morgner A, Lehn N, Andersen LP, et al. Helicobacter heilmannii-associated primary gastric low-grade MALT Iymphoma: complete remission after curing the infection. Gastroenterology 2000;118:821-8.

66. Andrew A, Wyatt JI, Dixon MF. Observer variation in the assessment of chronic gastritis according to the Sydney system. Histopathology 1994;25:317-22.

67. Christensen AH, Gjorup T, Hilden J, et al. Observer homogeneity in the histologic diagnosis of Helicobacter pylori. Latent class analysis, kappa coefficient, and repeat frequency. Scand J Gastroenterol 1992;27:933-9.

68. Bayerdorffer $\mathbf{E}$, Oertel $\mathrm{H}$, Lehn N, et al. Topographic association between active gastritis and Campylobacter pylori colonisation. J Clin Pathol 1989;42:834-9.

69. Graham DY, Opekun AR, Hammoud F, et al. Studies regarding the mechanism of false negative urea breath tests with proton pump inhibitors. Am J Gastroenterol 2003;98:1005-9.

70. Dickey W, Kenny BD, McConnell JB. Effect of proton pump inhibitors on the detection of Helicobacter pylori in gastric biopsies. Aliment Pharmacol Ther 1996; 10:289-93.

71. Trebesius K, Panthel K, Strobel S, et al. Rapid and specific detection of Helicobacter pylori macrolide resistance in gastric tissue by fluorescent in situ hybridisation. Gut 2000;46:608-14.

72. Lehours $\mathbf{P}$, Ruskone-Fourmestraux $A$, Lavergne $A$, et al. Which test to use to detect Helicobacter pylori infection in patients with low-grade gastric mucosaassociated lymphoid tissue lymphoma? Am J Gastroenterol 2003;98:291-5.

73. Eck M, Greiner A, Schmausser B, et al. Evaluation of Helicobacter pylori in gastric MALT-type lymphoma: differences between histologic and serologic diagnosis. Mod Pathol 1999;12:1148-51.

74. Gatta L, Vakil N, Ricci C, et al. Effect of proton pump inhibitors and antacid therapy on ${ }^{13} \mathrm{C}$ urea breath tests and stool test for Helicobacter pylori infection. $\mathrm{Am} \mathrm{J}$ Gastroenterol 2004;99:823-9. 
75. Dulbecco $\mathbf{P}$, Gambaro C, Bilardi $\mathrm{C}$, et al. Impact of long-term ranitidine and pantoprazole on accuracy of $\left[{ }^{13} \mathrm{C}\right]$ urea breath test. Dig Dis Sci 2003;48:315-21.

76. Malfertheiner P, Megraud F, O'Morain C, et al. Current concepts in the management of Helicobacter pylori infection: the Maastricht III Consensus Report. Gut 2007;56:772-81.

77. Fischbach W, Malfertheiner P, Hoffmann JC, et al. S3-guideline "helicobacte pylori and gastroduodenal ulcer disease" of the German society for digestive and metabolic diseases (DGVS) in cooperation with the German society for hygiene and microbiology, society for pediatric gastroenterology and nutrition e. V., German society for rheumatology, AWMF-registration-no. 021/001. Z Gastroenterol 2009:47:1230-63.

78. Zullo A, Hassan C, Andriani A, et al. Eradication therapy for Helicobacter pylori in patients with gastric MALT Iymphoma: a pooled data analysis. Am J Gastroenterol 2009;104:1932-7. quiz 8 .

79. Fischbach LA, van Zanten S, Dickason J. Meta-analysis: the efficacy, adverse events, and adherence related to first-line anti-Helicobacter pylori quadruple therapies. Aliment Pharmacol Ther 2004:20:1071-82.

80. Raderer M, Streubel B, Wohrer S, et al. Successful antibiotic treatment of Helicobacter pylori negative gastric mucosa associated lymphoid tissue lymphomas. Gut 2006:55:616-18.

81. Nakamura S, Matsumoto $\mathrm{T}, \mathrm{Ye} \mathrm{H}$, et al. Helicobacter pylori-negative gastric mucosa-associated lymphoid tissue lymphoma: a clinicopathologic and molecular study with reference to antibiotic treatment. Cancer 2006:107:2770-8.

82. Park HS, Kim YJ, Yang WI, et al. Treatment outcome of localized Helicobacter pylori-negative low-grade gastric MALT Iymphoma. World J Gastroenterol 2010;16:2158-62.

83. Montalban C, Santon A, Boixeda D, et al. Treatment of low grade gastric mucosaassociated lymphoid tissue lymphoma in stage I with Helicobacter pylor eradication. Long-term results after sequential histologic and molecular follow-up. Haematologica 2001;86:609-17

84. Roggero E, Zucca E, Pinotti G, et al. Eradication of Helicobacter pylori infection in primary low-grade gastric lymphoma of mucosa-associated lymphoid tissue. Ann Intern Med 1995;122:767-9.

85. Neubauer A, Thiede C, Morgner A, et al. Cure of Helicobacter pylori infection and duration of remission of low- grade gastric mucosa-associated lymphoid tissue lymphoma. J Natl Cancer Inst 1997:89:1350-5.

86. Castrillo JM, Montalban C, Obeso G, et al. Gastric B-cell mucosa associated lymphoid tissue lymphoma: a clinicopathological study in 56 patients. Gut 1992:33:1307-11.

87. Nakamura S, Matsumoto T, Suekane $\mathrm{H}$, et al. Long-term clinical outcome of Helicobacter pylori eradication for gastric mucosa-associated lymphoid tissue lymphoma with a reference to second-line treatment. Cancer 2005;104:532-40.

88. Morgner A, Thiede C, Bayerdorffer E, et al. Long-term follow-up of gastric MALT lymphoma after H. pylori eradication. Curr Gastroenterol Rep 2001;3:516-22.

89. Isaacson PG, Diss TC, Wotherspoon AC, et al. Long-term follow-up of gastric MALT lymphoma treated by eradication of $\mathrm{H}$. pylori with antibodies. Gastroenterology 1999:117:750-1.

90. Fischbach W, Goebeler-Kolve ME, Dragosics B, et al. Long term outcome of patients with gastric marginal zone B-cell lymphoma of mucosa associated lymphoid tissue (MALT) following exclusive Helicobacter pylori eradication therapy: experience from a large prospective series. Gut 2004;53:34-7.

91. de Mascarel A, Ruskone-Fourmestraux A, Lavergne-Slove A, et al. Clinical, histological and molecular follow-up of 60 patients with gastric marginal zone lymphoma of mucosa-associated lymphoid tissue. Virchows Arch 2005:446:219-24.

92. Savio A, Zamboni G, Capelli P, et al. Relapse of low-grade gastric MALT Iymphoma after Helicobacter pylori eradication: true relapse or persistence? Long-term posttreatment follow-up of a multicenter trial in the north-east of Italy and evaluation of the diagnostic protocol's adequacy. Recent Results Cancer Res 2000;156:116-24.

93. Fischbach W, Goebeler ME, Ruskone-Fourmestraux A, et al. Most patients with minimal histological residuals of gastric MALT lymphoma after successful eradication of Helicobacter pylori can be managed safely by a watch and wait strategy: experience from a large international series. Gut 2007;56:1685-7.

94. Hancock BW, Qian W, Linch D, et al. Chlorambucil versus observation after antiHelicobacter therapy in gastric MALT Iymphomas: results of the international randomised LYO3 trial. Br J Haematol 2009:144:367-75.

95. Liu H, Ruskon-Fourmestraux A, Lavergne-Slove A, et al. Resistance of t(11;18 positive gastric mucosa-associated lymphoid tissue lymphoma to Helicobacter pylori eradication therapy. Lancet 2001;357:39-40.

96. Zinzani PL, Frezza G, Bendandi M, et al. Primary gastric lymphoma: a clinical and therapeutic evaluation of 82 patients. Leuk Lymphoma 1995;19:461-6

97. Vaillant JC, Ruskone-Fourmestraux A, Aegerter P, et al. Management and long-term results of surgery for localized gastric lymphomas. Am J Surg 2000;179:216-22.

98. Sano T. Treatment of primary gastric lymphoma: experience in the National Cancer Center Hospital, Tokyo. Recent Results Cancer Res 2000:156:104-7.

99. Koch P, del Valle F, Berdel WE, et al. Primary gastrointestinal non-Hodgkin's lymphoma: II. Combined surgical and conservative or conservative management only in localized gastric lymphoma-results of the prospective German Multicenter Study GIT NHL 01/92. J Clin Oncol 2001;19:3874-83.

100. Kodera Y, Yamamura Y, Nakamura $S$, et al. The role of radical gastrectomy with systematic lymphadenectomy for the diagnosis and treatment of primary gastric lymphoma. Ann Surg 1998;227:45-50.
101. Kuo SH, Chen LT, Wu MS, et al. Long-term follow-up of gastrectomized patients with mucosa-associated lymphoid tissue lymphoma: need for a revisit of surgical treatment. Ann Surg 2008;247:265-9.

102. Aviles A, Nambo MJ, Neri N, et al. Mucosa-associated lymphoid tissue (MALT) lymphoma of the stomach: results of a controlled clinical trial. Med Oncol 2005:22:57-62.

103. Vrieling C, de Jong $\mathrm{D}$, Boot $\mathrm{H}$, et al. Long-term results of stomach-conserving therapy in gastric MALT Iymphoma. Radiother Oncol 2008;87:405-11.

104. Willich NA, Reinartz G, Horst EJ, et al. Operative and conservative management of primary gastric lymphoma: interim results of a German multicenter study. Int J Radiat Oncol Biol Phys 2000;46:895-901.

105. Pinotti G, Zucca E, Roggero E, et al. Clinical features, treatment and outcome in a series of 93 patients with low-grade gastric MALT lymphoma. Leuk Lymphoma 1997;26:527-37.

106. Binn M, Ruskone-Fourmestraux A, Lepage E, et al. Surgical resection plus chemotherapy versus chemotherapy alone: comparison of two strategies to treat diffuse large B-cell gastric lymphoma. Ann Oncol 2003;14:1751-7.

107. Ferreri AJ, Cordio S, Ponzoni M, et al. Non-surgical treatment with primary chemotherapy, with or without radiation therapy, of stage I-II high-grade gastric lymphoma. Leuk Lymphoma 1999:33:531-41.

108. Zullo A, Hassan C, Andriani A, et al. Treatment of low-grade gastric MALTlymphoma unresponsive to Helicobacter pylori therapy: a pooled-data analysis. Med Oncol 2010:27:291-5.

109. de Jong D, Aleman BM, Taal BG, et al. Controversies and consensus in the diagnosis, work-up and treatment of gastric lymphoma: an international survey. Ann Oncol 1999;10:275-80.

110. Thieblemont C, Dumontet C, Bouafia F, et al. Outcome in relation to treatment modalities in 48patients with localized gastric MALT Iymphoma: a retrospective study of patients treated during 1976-2001. Leuk Lymphoma 2003;44:257-62.

111. Tsang RW, Gospodarowicz MK, Pintilie M, et al. Stage I and II MALT Iymphoma: results of treatment with radiotherapy. Int J Radiat Oncol Biol Phys 2001;50:1258-64.

112. Isaacson PG. Gastric MALT Iymphoma: from concept to cure. Ann Oncol 1999;10:637-45.

113. Burgers JM, Taal BG, van Heerde $P$, et al. Treatment results of primary stage I and II non-Hodgkin's lymphoma of the stomach. Radiother Oncol 1988:11:319-26.

114. Kocher M, Muller RP, Ross D, et al. Radiotherapy for treatment of localized gastrointestinal non-Hodgkin's lymphoma. Radiother Oncol 1997;42:37-41.

115. Schechter NR, Portlock CS, Yahalom J. Treatment of mucosa-associated lymphoid tissue lymphoma of the stomach with radiation alone. J Clin Oncol 1998; 16:1916-21.

116. Tsang RW, Gospodarowicz MK, Pintilie M, et al. Localized mucosa-associated lymphoid tissue lymphoma treated with radiation therapy has excellent clinical outcome. J Clin Oncol 2003;21:4157-64.

117. Tomita N, Kodaira T, Tachibana $\mathrm{H}$, et al. Favorable outcomes of radiotherapy for early-stage mucosa-associated lymphoid tissue Iymphoma. Radiother Oncol 2009;90:231-5

118. Sato $\mathbf{M}$, Uematsu $\mathbf{M}$, Hama $Y$, et al. Low-dose induction radiotherapy for stomach conservation in patients with massive gastric lymphoma. Tumori 2000;86:286-8.

119. Gospodarowicz MK, Pintilie M, Tsang R, et al. Primary gastric lymphoma: brief overview of the recent Princess Margaret Hospital experience. Recent Results Cancer Res 2000;156:108-15.

120. Della Biancia C, Hunt M, Furhang E, et al. Radiation treatment planning techniques for lymphoma of the stomach. Int $\mathrm{J}$ Radiat Oncol Biol Phys 2005; 62:745-51.

121. Lawrence TS, Davis MA, Maybaum J. Dependence of 5-fluorouracil-mediated radiosensitization on DNA-directed effects. Int J Radiat Oncol Biol Phys 1994;29:519-23.

122. Hammel P, Haioun C, Chaumette MT, et al. Efficacy of single-agent chemotherapy in low-grade B-cell mucosa- associated lymphoid tissue lymphoma with prominen gastric expression. J Clin Oncol 1995:13:2524-9.

123. Jager G, Neumeister $P$, Quehenberger $F$, et al. Prolonged clinical remission in patients with extranodal marginal zone B-cell lymphoma of the mucosa-associated lymphoid tissue type treated with cladribine: 6 year follow-up of a phase II trial. Ann Oncol 2006;17:1722-3.

124. Troch M, Zielinski C, Raderer M. Absence of efficacy of thalidomide monotherapy in patients with extranodal marginal zone B-cell lymphoma of the mucosaassociated lymphoid tissue (MALT lymphoma). Ann Oncol 2009;20:1446-7.

125. Wohrer S, Raderer M, Kaufmann $\mathrm{H}$, et al. Effective treatment of indolent nonHodgkin's lymphomas with mitoxantrone, chlorambucil and prednisone. Onkologie 2005;28:73-8.

126. Raderer M, Wohrer S, Bartsch R, et al. Phase II study of oxaliplatin for treatment of patients with mucosa-associated lymphoid tissue lymphoma. J Clin Oncol 2005;23:8442-6.

127. Raderer $\mathbf{M}$, Jager $\mathrm{G}$, Brugger $\mathbf{S}$, et al. Rituximab for treatment of advanced extranodal marginal zone B-cell lymphoma of the mucosa-associated lymphoid tissue lymphoma. Oncology 2003:65:306-10.

128. Conconi A, Martinelli G, Thieblemont $\mathrm{C}$, et al. Clinical activity of rituximab in extranodal marginal zone B-cell lymphoma of MALT type. Blood 2003;102:2741-5

129. Wohrer S, Troch M, Zwerina J, et al. Influence of rituximab, cyclophosphamide, doxorubicin, vincristine and prednisone on serologic parameters and clinical course in lymphoma patients with autoimmune diseases. Ann Oncol 2007;18:647-51. 
130. Levy M, Copie-Bergman C, Molinier-Frenkel V et al. Treatment of t(11;18)-positive gastric mucosa-associated lymphoid tissue lymphoma with rituximab and chlorambucil: clinical, histological, and molecular follow-up. Leuk Lymphoma 2010;51:284-90.

131. Salar A, Domingo-Domenech E, Estany C, et al. Combination therapy with rituximab and intravenous or oral fludarabine in the first-line, systemic treatment of patients with extranodal marginal zone B-cell lymphoma of the mucosa-associated lymphoid tissue type. Cancer 2009;115:5210-17.

132. Copie-Bergman C, Gaulard P, Lavergne-Slove A, et al. Proposal for a new histological grading system for post-treatment evaluation of gastric MALT lymphoma. Gut 2003;52:1656.

133. Yeh HZ, Chen GH, Chang WD, et al. Long-term follow up of gastric low-grade mucosa-associated lymphoid tissue lymphoma by endosonography emphasizing the application of a miniature ultrasound probe. J Gastroenterol Hepatol 2003;18:162-7.

134. Puspok A, Raderer M, Chott A, et al. Endoscopic ultrasound in the follow up and response assessment of patients with primary gastric lymphoma. Gut 2002;51:691-4.

135. Di Raimondo F, Caruso L, Bonanno G, et al. Is endoscopic ultrasound clinically useful for follow-up of gastric lymphoma? Ann Oncol 2007;18:351-6.

136. Janssen J. The impact of EUS in primary gastric lymphoma. Best Pract Res Clin Gastroenterol 2009;23:671-8.

137. Morgner A, Bayerdorffer E, Neubauer A, et al. Helicobacter pylori associated gastric B-cell MALT lymphoma: predictive factors for regression. Gut 2001:48:290-2.

138. Copie-Bergman C, Locher C, Levy M, et al. Metachronous gastric MALT lymphoma and early gastric cancer: is residual lymphoma a risk factor for the development of gastric carcinoma? Ann Oncol 2005;16:1232-6.

139. Capelle LG, de Vries AC, Looman CW, et al. Gastric MALT lymphoma: epidemiology and high adenocarcinoma risk in a nation-wide study. Eur J Cancer 2008:44:2470-6.

\section{Editor's quiz: GI snapshot}

\section{Unexplained gastrointestinal dysmotility: the clue may lie in the brain}

\section{CLINICAL PRESENTATION}

A 23-year-old male was referred to our tertiary intestinal failure unit for evaluation and nutritional support. He had presented to a neighbouring hospital with a 2 year history of episodic vomiting, abdominal pain and progressive weight loss. Evaluation at that hospital had suggested an annular pancreas causing duodenal narrowing, and he underwent a surgical resection and gastrojejunostomy. Symptoms persisted for $>3$ months postsurgery and a working diagnosis of severe gastrointestinal dysmotility was made following further endoscopic and radiological investigation (figure 1). Following further nutritional decline, parenteral nutrition was commenced and he was referred to our hospital for further management.

On admission to our unit, he was cachectic with a body mass index of $13.6 \mathrm{~kg} / \mathrm{m}^{2}$. MRI of the brain was performed to exclude a central cause for his symptoms (figure 2). Shortly thereafter he developed subacute, progressive, lower limb weakness with associated sensory disturbance. Neurological examination revealed subtle bilateral ptosis, slight impairment of upward gaze and depressed lower limb reflexes. Nerve conduction studies revealed a generalised demyelinating polyneuropathy.

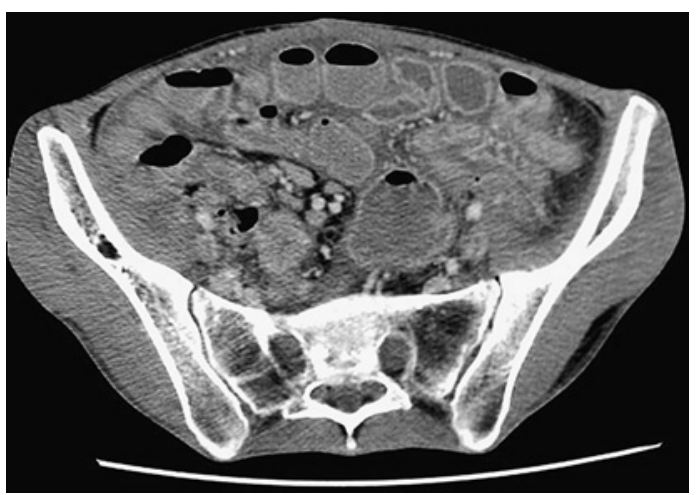

Figure 1 An intravenous contrast-enhanced CT of the abdomen and pelvis, revealing multiple loops of small bowel with fluid and gas distension but no transition point, suggestive of ileus/intestinal dysmotility.

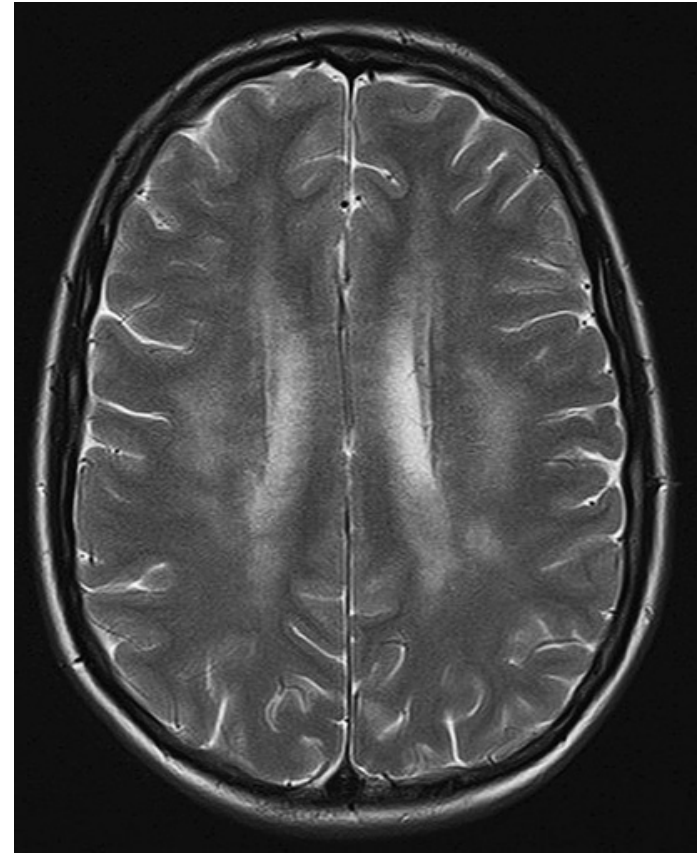

Figure 2 Axial, $T_{2}$-weighted MRI of the brain.

\section{QUESTIONS}

What does the MRI of the brain show?

Is there a unifying diagnosis?

See page 805 for the answers

Adrian Parry-Jones, ${ }^{1}$ Peter Paine, ${ }^{2}$ Ranjit Ramdass, ${ }^{3}$ Neal Townsend, ${ }^{4}$ Richard Hammonds, ${ }^{5}$ Antje Teubner, ${ }^{6}$ Jon Shaffer, ${ }^{6}$ Paul Cooper, ${ }^{1}$ Simon Lal ${ }^{6}$

${ }^{1}$ Department of Neurology, Salford Royal Hospital, Salford, UK; ${ }^{2}$ Department of Gastroenterology, Salford Royal Hospital, Salford, UK; ${ }^{3}$ Department of Neurophysiology, Salford Royal Hospital, Salford, UK; ${ }^{4}$ Department of Radiology, Salford Royal Hospital, Salford, UK; ${ }^{5}$ Department of Gastroenterology, North Manchester General Hospital, Manchester, UK; ${ }^{6}$ Intestinal Failure Unit, Salford Royal Hospital, Salford, UK

Correspondence to Dr Adrian Parry-Jones, Brain Injury Research Group, Clinical Sciences Building, Salford Royal Hopsital, Stott Lane, Salford M6 8HD, UK; adrian.parry-jones@manchester.ac.uk

\section{Competing interests None}

Patient consent Obtained

Provenance and peer review Not commissioned; externally peer reviewed.

Published Online First 2 July 2010

Gut 2011;60:758. doi:10.1136/gut.2009.202465 